\title{
Max Weber's Methodology: The Method of Falsification Applied to Text Interpretations
}

\author{
Christian Etzrodt \\ Law Department, Yamanashi Gakuin University, Kofu, Japan \\ Email: etzrodtc@hotmail.com
}

Received 9 June 2014; revised 12 July 2014; accepted 20 July 2014

Copyright (C) 2014 by author and Scientific Research Publishing Inc.

This work is licensed under the Creative Commons Attribution International License (CC BY). http://creativecommons.org/licenses/by/4.0/

c) (i) Open Access

\begin{abstract}
Text interpretations are usually leading to ambiguous results. This is especially the case for the interpretation of Max Weber's methodology. I discuss Thomas Burger's interpretation that Weber applied Rickert's methodology and that he never developed his own standpoint regarding the methodological problems. In contrast to this view, I propose an alternative interpretation based on the Methodenstreit in economics and the philosophies of Kant and Rickert. In my opinion Weber offered a very unique solution to an old philosophical problem, which resulted in a complete break with the Platonic and Aristotelian tradition. His solution is what I call the postulate of internal consistency (a logical consistent application of an arbitrary scheme of interpretation). I will use Popper's method of deductive falsification to decide if Burger's or my interpretation produces fewer contradictions.
\end{abstract}

\section{Keywords}

Max Weber, Methodology, Ideal-Types, Verification, Intuition, Falsification, Postulate of Logical Cosistency

\section{Introduction}

Many sociologists interpret Max Weber's methodology in a specific direction, with the aim to use his methodology for their own problems. But they usually ignore aspects, which seem to be unimportant for them. This is in principle not problematic. But a selective interpretation becomes a problem, if with Weber's authority the own methodological approach is claimed to be the only acceptable in sociology (Scaff, 1984: p. 191). In such a case it is not anymore justified to overlook some aspects of Weber's methodology or the problem, which Weber wanted to solve (cf. Burger, 1976: p. ix).

But it is possible to achieve an interpretation, which unquestionable gives an accurate description of his me- 
thodology? In the past, sociologists clearly failed to provide such an interpretation. Is it therefore impossible? Are interpretations necessarily arbitrary and relative? I do not believe so. I propose here the method of falsification as an alternative method for text interpretations, in the hope that we will get closer to the truth.

\section{Thomas Burger's Interpretation of Max Weber's Methodology}

Thomas Burger's interpretation of Weber's methodology is based on the hypothesis that Weber never developed his own methodology but just applied the methodology of Heinrich Rickert. Burger states "that this agreement is almost total within the era under consideration, i.e., the theory of concept formation and its epistemological foundation" and that Weber "never changed his views in any relevant way" (Burger, 1976: p. 7).

Burger (1976: p. 4) cites Tenbruck's hypothesis that Weber was not really interested in methodology, but was temporarily pushed into this field by the crisis in economics. The sources of Weber's methodological writings are not philosophical problems but auxiliary methodological considerations of a specialized scientist. Methodological reflection is a means but not an end (Tenbruck, 1959: pp. 582-583). Burger (1976: p. 7) agrees with Tenbruck that Weber was not a methodologist, but he rejects Tenbruck's conclusion that Weber "was not in possession of a coherent and systematic methodological theory." For Burger, Weber had such a systematic methodology, but it was not his own. It was the methodology of Heinrich Rickert.

Burger (1976: p. xv) defines the problem, which Max Weber wanted to solve and which he took from Heinrich Rickert, as follows:

$\mathrm{B}_{1}$ "What is it that makes the writing of history a justifiable undertaking?"

Burger reformulates this question in a more "general" way.

$\mathrm{B}_{2}$ "Of all the possible things that one could want to know, which ones are a legitimate object of investigation?”

This reformulation is actually not more general, but much more concrete, because it rejects one of two possible applications of a theory. The application of a theory can have two functions. A theory can be applied to test its validity, or a theory can be applied as a heuristic scheme of interpretation for the understanding of a singular case, without the aim to verify or falsify the theory. Burger's formulation implies therefore that Weber's methodology is not about the question "how we can check and improve and expand the [general] knowledge which we have” (cf. also Burger, 1976: pp. 76-77).

Burger's strategy to support his hypotheses begins with an examination of Heinrich Rickert's methodology. I will give a short summary of Burger's description of Rickert's methodology, but I will also add information about Rickert's relation to Immanuel Kant. In my opinion, Kant is important for the understanding of Rickert and Weber.

1) Rickert agreed with Kant's idea of the qualitatively and quantitatively infiniteness of reality and the need to interpret it (Rickert, 1921b: p. 33; Burger, 1976: p. 21).

2) Rickert accepted Kant's starting point, that the mind forms the sensual experience into knowledge (Rickert, 1921a: p. 334).

3) But Rickert added to Kant's genetic a priori a value-related perspective. Kant showed that human beings have the inborn capacity to choose elements of the reality and to bring them into a logical (e.g. causal) form, but he did not explain, which elements are chosen. Rickert explained this choice of the elements by their relation to values. The values are determining the perspective and therefore what parts of the physical world are perceived as "real” (Rickert, 1921a: p. 332; cf. Burger, 1976: pp. 14-16).

4) Rickert rejected the left open possibility in Kant's work that a connection exists between the mind construction and the real thing (Ding an sich). It is questionable, if for Kant actors can force causality on nature, because the real things are following causal laws, or if this can be done independent of the existing or non-existing causality in the nature. For Rickert on the other hand neither the content of an object nor the causal relation between objects can be perceived, their images are only products of the mind (Rickert, 1921a: pp. 126, 334, 347; Burger, 1976: pp. 15-16, 20).

5) Rickert concluded that the mind is therefore producing the objective reality by accepting values or rejecting un-values (Rickert, 1921a: pp. 171, 188, 199, 348; cf. Burger, 1976: p. 15).

6) Rickert applied finally the Kantian problem of "How is science possible?" to the historical sciences (Burger, 1976: p. 13). Do the historical sciences belong to science or metaphysics?

This is the problem formulated by Burger as the question $\mathrm{B}_{1}$ and $\mathrm{B}_{2}$ which Rickert and Weber tried to solve. 
However, out of Rickert's assumptions arose a new problem, which had to be solved first, before the historical sciences could be declared a science. If every interpretation is based on the subjective value choices-and therefore on a subjective perspective, then the objectivity of knowledge in the historical sciences is not anymore guaranteed (Burger, 1976: pp. 17-18). Rickert's solution to this problem was that an ultimate value is used as a normative criterion accepted by everyone to produce intersubjectively valid historical interpretations (Rickert, 1921a: pp. 175-176, 346; Burger, 1976: pp. 16, 18, 41-42, 49-51). He furthermore stated that objective knowledge can be produced in the form of concept definitions. Concepts are the result of an inductive abstraction. They represent a number of instances, which share several characteristics (Burger, 1976: pp. 19-21, 26-27).

As a next step Rickert accepted Windelbrand's definitions of two different types of sciences: nomological and ideographic sciences. Nomological sciences are using abstractions to build general concepts in the form of laws like physics, there as ideographic sciences are using abstractions to build individual concepts like the historical sciences (Burger, 1976: pp. 22-23). An individual concept can be described as the sum of several general concepts in their unique combination. A singular phenomenon is therefore the result of a specific constellation of several causal effects (Burger, 1976: pp. 48-49).

In this sense are general laws not important for the historical sciences. General concepts are a means but not an aim. They are important for constructing individual concepts (Burger, 1976: pp. 33-34). But laws of history cannot be constructed, because individual (historical) concepts cannot refer to something general (Burger, 1976: p. 47).

After describing Rickert's methodology, Burger argues that Weber agreed in all relevant aspects with Rickert: he accepted 1) the differences between generalizing and individualizing sciences, 2) the idea of individual concepts as a sum of a unique formation of general concepts, 3) that concept definitions are objective representations of reality, 4) an ultimate value as basis for all researchers' perspectives, and 5) finally, Rickert's problem of how to choose the essential elements for a description of a singular phenomenon.

Related to the first point, Burger remarks that Weber rejected the thesis that nomological knowledge is the only legitimate form of scientific knowledge. And he shared Rickert's view that the individualizing method is as scientific as the formulation of general laws. Both methods of abstraction fulfill their specific tasks and they cannot replace each other (Weber, 1985: p. 187; Burger, 1976: pp. 60, 74). These methods of abstraction are a "process of selecting the essential phenomena from concrete reality" (Burger, 1976: pp. 73-74; cf. Weber, 1985: pp. 4, 13, 13 n.1), and "to abstract" means "to take away" or to ignore unimportant parts of reality (Burger, 1976: p. 74). The method of generalizing is focusing on one element or one relation between two elements in all cases and all other elements are ignored (Weber, 1985: p. 5; Burger, 1976: p. 69). The method of individualizing is dealing with all elements and their relations in one case in connection to the previous case and all other cases are ignored.

Burger furthermore stated that Weber agreed with Rickert that applying one of these two methods would solve the problem of the infinite multiplicity of empirical reality (Burger, 1976: p. 70). I find this statement astonishing, because Hume showed that a method of generalizing in the sense of inductive verification fails, there as Kant showed that also the method of inductive intuition does not overcome the infinite multiplicity of reality for general statements. Both methods fail, because it is impossible to know all cases and to infer from the known to the unknown cases. And in the same way the method of individualizing fails as Rickert and Weber emphasized, because it is impossible to perceive all elements in one case. This is the content of their statement of the quantitative and qualitative infiniteness of reality (Rickert, 1921a: p. 121; Rickert, 1921b: p. 29; Rickert, 1921c: p. 33; Weber, 1985: p. 4). Therefore the acceptance of two different methods of abstraction is rather the definition of the problem than the solution. The problem is to guarantee the truth of our statements although it is based on incomplete experience, which leaded Rickert and Weber to the problem of selecting elements of the infinite reality. However, this is a problem for both types of sciences: for generalizing as well as for individualizing sciences.

Burger states referring to the second point that for Weber as for Rickert an individual historical phenomenon in the sense of a unique constellation is causally explained by the previous individual historical phenomenon and so on (Weber, 1985: p. 172; Burger, 1976: p. 86). In detail an individual phenomenon can be described as the result of a specific combination of general causal effects (Weber, 1985: pp. 201-202; Burger, 1976: p. 132), random effects, and individual effects in the sense of human actors' motives in the preceding situation (cf. Burger, 1976: p. 86). General concepts are in the historical sciences a means but not an end. They are important for the understanding of phenomena "which are significant from concrete individual viewpoints" (Weber, 1985: pp. 208-209; Burger, 1976: p. 69, cf. p. 167). However, historical phenomena cannot be deduced completely from 
general concepts or causal laws (Weber, 1985: pp. 13, 18, 28, 174; Burger, 1976: p. 76), simply because the unique constellation of the effects of these general laws which constitute the phenomenon cannot be explained by an all determining holistic law itself.

Concerning the third point, scientific knowledge was for Weber an "ordering in thought of empirical reality" (denkende Ordnung der empirischen Wirklichkeit) or an "intellectual mastery of empirical data" (Weber, 1985: pp. 150, 208; Burger, 1976: p. 61). The emphasize of "empirical” suggests that Weber did not agreed with Rickert's rejection of Kant's Ding an sich, and that for him the mental constructions of the reality were dependent on the real facts. However, Burger argues against this interpretation, because he tries to avoid any connection between Max Weber and positivism. And this can be done most successfully, if Weber was not interested in the reality at all but only in the mental representation of the reality in the mind (Burger, 1976: p. 61).

Burger describes therefore "concrete facts" as "mental images", which are the material of concept formation for Rickert and Weber (Burger, 1976: p. 62). And he explicitly states that the material of concept formation is a "fact" and not an "experienced sensation." However, Burger admits that sensations are not completely unimportant, because the mind transforms them—-through a categorical judgment-into facts (Burger, 1976: p. 63; Weber, 1985: pp. 72-73, 109-110). Nevertheless, Burger (1976: p. 68) maintains that concepts are the aim of scientific knowledge and not a means to acquire information about reality ${ }^{2}$.

The objectivity of the concepts is guaranteed in Burger's interpretation by the application of categories, for example the category of “causality” (Burger, 1976: pp. 64-65, 70; cf. Weber, 1985: pp. 89, 212-213). A concept is an objective representation of the empirical reality, if it was formed correctly (Burger, 1976: p. 69).

It is scientific knowledge because its content is facts and its form is conceptual (whereas the content of factual knowledge is ideas of sensations, and its form is categorical) (Burger, 1976: p. 70).

Then Burger (1976: pp. 67-68) suggests that Weber applied an essentialistic method for selecting the facts, which are worth knowing, although he states in a footnote clearly that "it hardly needs emphasis that 'essential', as Weber uses it, has nothing to do with the 'nature' of things" (Burger, 1976: p. 191 n. 12). Of course, Burger does not say directly that Weber is an essentialist, but he translates "wesentlich" as "essential", although in the context of Weber's work "important" would be the far better translation (cf. Weber, 1985, pp. 5, 86, 171 cited by Burger, 1976, p. 67). This gives the impression that Weber had as Carl Menger an Aristotelian philosophy for his concept formation in mind, a position which he clearly rejected. It is my impression that Burger deliberately chose this translation, because he seems to be well aware of the impossibility to verify a general concept inductively, because the future cannot be known (Weber, 1985, pp. 4, 14, 75 n. 2, 92 n.1, 237; Burger, 1976: pp. 32, 65). But he states that Weber applied a method of induction (Burger, 1976: p. 205). Therefore the gap between the known cases and all cases including the unknown cases can only be bridged inductively by the method of intuition. But this would mean that Weber was a methodological essentialist ${ }^{3}$.

All efforts to acquire intellectual knowledge of the infinite reality through the finite human mind, therefore, rest on the tacit assumption that in each case only a finite part of this reality can be scientifically grasped, and that it alone is "essential" in the sense of "worth knowing" (Burger, 1976: p. 73).

The problem arises now for Burger to explain, why Weber called the propositions of the classical economic theory "ideal types" and not genuine general concepts or "laws of nature” (Weber, 1985, pp. 140, 179, 189-190), if they were for him objective valid. For Burger Weber regarded the economic propositions-when applied to all the concrete empirical phenomena to which they are taken to refer-as only approximately correct. "Ideal types" were for Weber heuristic schemes of interpretation and not a hypothesis about the causal connections in reality (Burger, 1976: pp. 120-121), and they are therefore not rejected, if they fail to describe a concrete instance accurate (Burger, 1976: p. 204 n. 31). However, Burger's solution is that the objective valid "ideal types" will describe a concrete instance correctly, "if the world would function according to certain specified principles" (Burger, 1976: p. 133). In other words, the concepts as constructions of the mind are objective valid, but they

\footnotetext{
${ }^{1}$ Burger refers here to Weber (1985: p. 89), but I cannot find on this page a statement of Weber, which supports Burger's interpretation. ${ }^{2}$ However, Weber (1985: p. 6) declared that concepts are for him a means for selecting the important elements out of the infiniteness of reality.

${ }^{3}$ Compare in relation to this argument Antoni’s Max Weber interpretation to which Burger (1976: p. 205) also refers: Antoni (1959: pp. 172, 174) describes “ideal types” as “essences” similar to the philosophical tradition of Plato and Aristotle. In this sense Burger (1976: p. 127; cf. p. 131) rejects also the position that Weber's concepts are nominally defined. But if they are not nominally defined, how are they defined instead? I can only conclude that they must be then defined essentially.
} 
can only be called laws, if in reality the same causal laws determine the processes as they there constructed by the human minds. And because we cannot know anything about reality, Weber called these concepts "ideal types" (cf. Burger, 1976: pp. 165-166).

Burger concludes then in relation to the fourth point that Weber applied Rickert's solution to the problem of selecting elements of reality. "Cultural interests" based on values determine what is significant for the researcher (Weber, 1985: p. 181; Burger, 1976: p. 80). And the term "cultural interests” implies for Burger (1976: p. 80) that every member of a society has values relating to common concerns. "Otherwise he would not be interested in those phenomena in which other persons' values relating to collective concerns are embodied." However, Burger has to admit that Weber was not stating this explicitly, but he assumes that Rickert's argumentation was widely known, and that Weber regarded it as unnecessary to make his point clear. A historical description is therefore objective, if the selection of the essential elements was based on a general value of the researcher's culture (Burger, 1976: p. 80).

In other words, Burger suggests that the general values of the historian's society are determining the selection of the essential elements in the description of history. And because all historians of a specific society share this same general value, the result of writing history will be objective. However, the problem is that only Burger (1976: pp. 81-82) speaks of "general cultural values" there as Weber was just talking of "cultural values". To close this gab, Burger states that a great number of general cultural values exist and that they "are too many to allow the description of all the constellations of phenomena to which they are attached, and the historical developments of all these phenomena, in one single historical account” (Burger, 1976: p. 81). Therefore is the historian "free" to choose the guiding values (Weber, 1985: p. 124 n. 1; Burger, 1976: p. 81). But is the result of historical writings in this case still objective? Burger has to admit that for Weber the historical sciences are not objective in this sense, because a plurality of viewpoints must be accepted (Weber, 1985: pp. 170, 184; Burger, 1976: pp. 82, 84). Burger (1976: p. 84) concludes therefore that the objectivity of the historical sciences can be achieved, if history is written from all viewpoints related to the general cultural values of the researchers' society.

Therefore cultural values and with them the viewpoints of history are infinite, because different societies or the same society in different times may have different cultural values. But in the same time they are finite for a society in a "specific moment or period in time" (Burger, 1976: p. 87). And the objectivity of historical writings is only given for historians of the same society in the same time period. Burger finally discusses the point that "there is unanimous agreement on the opinion that Rickert postulated the existence of absolutely valid values which can serve as viewpoints for historians, whereas Weber maintained that they are 'subjective"” (Weber, 1985: p. 183; cf. von Schelting, 1934: p. 228; Fleischmann, 1964: p. 198). Burger rejects this interpretation and states that Weber's text is in this case ambiguous (Burger, 1976: p. 87). He argues that Weber did accept for the natural sciences concepts which contain potential judgments of general validity (Weber, 1985: p. 4) and he therefore did accept "the idea of absolutely universal knowledge", although the method of induction is based only on "an empirically limited number of facts only"-in other words Weber believed in essential definitions of concepts based on intuition. And if Weber was an essentialist in relation to the natural sciences, it would be illogical to assume something else for the historical sciences (Burger, 1976: p. 88). And when Weber was talking about "subjective" viewpoints, he was not clearly separation his belief in general cultural values from "the fact that different people are attracted to different topics and viewpoints, and the fact that viewpoints change over time” (Burger, 1976: p. 89).

Burger (1976: p. 64; Weber, 1985: pp. 134-135) points out concerning the fifth point that Weber was separating two different concepts of causality: one typical for the generalizing ("natural”) sciences and one typical for the individualizing ("historical") sciences. For the generalizing sciences the concept of causality means a causal law, the regular appearance of a cause and an effect, like fire and heat. In the individualizing sciences the meaning of causality refers to the idea that one singular phenomenon was caused by a specific preceding other singular phenomenon. The idea of regularity loses its importance, if the researcher looks at a singular phenomenon as a unique constellation of causal regularities that was caused by other singular phenomena with their unique con-

\footnotetext{
${ }^{4}$ Another statement of Burger seems to contradict my interpretation: "by calling the contents of ideal types 'unreal' [Weber] did not want to convey the idea that they are free inventions of the imagination but merely that they describe phenomena which in principle are empirically possible but have failed to materialize as a result of factual circumstances” (Burger, 1976: p. 124). This would imply that "ideal types” are not different to laws of the natural sciences, which are also empirically possible and materialize only, if specific situational or initial conditions are given. But I do not think that Burger wanted to say this.
} 
stellations of causal regularities (Weber, 1985: pp. 134-135; Burger, 1976: p. 64).

Burger claims finally that Weber rejected the equation of "causal law" and "causality", but in all the references he gives to support his interpretation, Weber stated only his rejection of holistic causal laws (Weber, 1985: pp. 144, 178, 186). Holistic causal laws could not be the aim for the historical sciences, since Weber regarded history as an individualizing science, which uses causal laws only as a tool to describe some aspects of a singular phenomenon. Burger furthermore criticizes Julien Freund for his interpretation that Weber was accepting and using the two different concepts of causality as "the idea of rational action, a sort of dynamic between two qualitatively different phenomena, on the one hand; and [as] the idea of subsumption under a general rule, on the other” (Freund, 1968: pp. 49-50). It is substantial for Burger's argumentation to dismiss any interest of Weber in causal regularities (Burger, 1976: p. 93), because he cannot justify otherwise his hypothesis $B_{2}$ that Weber's problem was the selection of important elements of reality and not to check and improve and expand knowledge. The latter problem would directly lead to the problem of the truth of our general knowledge, which is the problem of positivism.

As a consequence Burger concludes that Weber advocated the method of understanding (Verstehen) of the "inner states" of human actors in contrast to the grasping (Begreifen) of meaningless facts. In this sense Weber was striving for the knowledge of the human actors' motives and plans, "which cause their actions and thereby give these actions their subjective meanings". And he therefore was not interested in the causal forces, which might have an impact on the actions too. Weber was interested in "culture" and not in "nature" (Burger, 1976: p. 103).

Finally, Burger comes to the conclusion that Weber's sociological program "to formulate type concepts and generalized uniformities of empirical processes" (Weber, 1968: p. 19) should not be confused with "the formulation of universal laws and their subsequent testing in order to confirm or falsify them” (Burger, 1976: pp. 137138). In Burger's interpretation sociology is only a complementary science for the historical sciences and the only task is to construct "ideal worlds" or concepts and schemes of interpretation as a heuristic tool. Therefore Burger's hypothesis $B_{2}$ that Weber's problem was the selection of essential elements out of the infinite reality seems to be justified.

\section{Critique of Burger's Interpretation of Weber's Methodology}

I do not agree with Burger's interpretation of Weber's methodology, although I found his analysis in large parts important for a better understanding of Weber's work. However, Burger's main thesis that Weber just applied Heinrich Rickert's methodology is for me not acceptable. Weber shared Rickert's problem concerning the objectivity of the historical sciences, but he solved the problem in a different way. In my opinion, the weak point of Burger's interpretation is the mostly exclusive reference to Rickert's methodology, although he states that Weber was not a methodologist, and that he was only pushed into this field, because of the methodological problems in economics. I would guess that it is then as important to analyze the problems in economics in Weber's time to understand what he wanted to solve with Rickert's methodology.

In Weber's time economics in the German speaking area was divided into two schools: the German Historical School of Gustav Schmoller and the Austrian School of Economics of Carl Menger. These two schools were in a quarrel - the so-called Methodenstreit-about the correct approach in economics. Schmoller advocated holistic historical analyses of the economy and the society, whereas Menger demanded a deductive approach based on general economic laws combined with a methodological individualism. The Methodenstreit can be therefore characterized as a conflict between holism and individualism on the one hand and an inductive historical approach — where historical cases are the starting point and the general laws the aim—and a deductive theoretical approach - where the general laws are the starting point and the description of historical cases is the aim (Hansen, 1968: p. 139; Schluchter, 1989: p. 4). However, this is only the foreground of this quarrel. In fact the methodological core of both schools was not that different. Schmoller wanted to form general laws with the method of inductive verification based on extensive studies of historical cases. It was his aim to formulate general statements which do not contradict the collected knowledge, but to justify the validity of these statements he demanded a large number of historical cases (Hansen, 1968: pp. 151-152). Menger shortened this procedure by the method of inductive intuition. He formed abstract general laws based on his knowledge and stated that these laws are a priori true (Hansen, 1968: p. 162). It is important to realize that from a Kantian or Neo-Kantian point of view both methodological approaches are fundamentally wrong. Immanuel Kant accepted David Hume's 
proof that a logical consistent method of inductive verification is impossible. It is impossible, because we cannot know the future and we are not allowed to draw any inferences from the limited known cases to all cases including the unknown cases (Hume, 1978: pp. 89, 139). Inferences from the known to the unknown would be only reasonable, if nothing changes in reality, but this is not the case (Hume, 1978: p. 89). Kant on the other hand showed that also the method of inductive intuition produces no valid results. Intuition leads for Kant to metaphysics but not to empirical sciences. This is the topic of Kant's Critique of Pure Reason. My first conclusion is therefore that Weber had a profound knowledge of methodology and philosophy, because he would have never realized the importance of Rickert's methodology for the Methodenstreit, if he would not have known Kant's philosophy very well, since the main problem of both economic schools was not clearly discussed in the Methodenstreit (cf. Turner \& Factor, 1984: p. 39; Honigsheim, 1968: pp. 28-29).

A second aspect is important in relation to the Methodenstreit, which do contemporary sociologists not often realize, but which is probably the key for the understanding of Max Weber's methodology. It is the question why Menger replaced the holistic inductive approach of the dominant German Historical School with a subjective deductive approach. The reason of this step was the failure of the German Historical School to explain one of the most important aspects of economics: price changes (Hayek, 1973: pp. 3, 5). Prices were regarded in the Historical School as objective values depending only on the good itself. For example Karl Marx said that prices are equivalent to the working time needed to produce the good. However, such definitions can only describe fixed prices, but they fail to explain changes of prices. It was the marginal revolution leaded by Menger, Jevons, and Walras, which solved this problem. Menger explained prices as the result of the subjective needs of the actors and the objective conditions to satisfy this needs (Hayek, 1973: p. 6).

These two elements - the subjective motives of the actors and the objective restrictions-are still today the forming elements of the modern economic theory. It is the foundation of the economic logic of choice or the economic calculus (Hayek, 1973: p. 7). And it is the formulation of the basic idea of the methodological individualism (Hayek, 1973: p. 8). But the problem of formulating true statements about the observed actors' motives leaded Menger to postulate that all actors are behaving rational. To avoid a psychological reductionism Menger stated that the rationality principle is a priori true (Menger, 1883: p. 42 [1985: p. 62]). Therefore, Menger's non-psychological solution to the explanation problem of price changes forced him to give up the method of inductive verification and the holistic approach.

Max Weber's position in the Methodenstreit can now be described like this: Weber had the same scientific interests as Gustav Schmoller (Hennis, 1994: pp. 115-117). Weber's aim was the description of historical processes, especially the phenomenon of Western modernity. But he accepted Menger's solution to the problem of price changes and therefore he accepted the methodological individualism (cf. Burger, 1994: p. 94) and a priori given general concepts as starting point (cf. Hennis, 1994: p. 113). Furthermore the distinction between individual subjective motives and the objective forces of the situation became an important aspect of both his theoretical and historical writings. In fact, Weber's historical writings can be seen as an application of Menger's marginal utility theory to historical problems. However, Weber did not accept Menger's rationality principle and replaced it with his classification system of action types. And finally Weber rejected the methodologies of both Schmoller and Menger, because both economic schools were not able to guarantee the truth of their statements, although they claimed to produce objective results (cf. Hennis, 1994: p. 110).

To solve the methodological problems he turned to the Neo-Kantian philosophy of Heinrich Rickert. I agree with Burger that Weber had no objections against the distinction between generalizing and individualizing sciences, and that for him sociology belonged to the generalizing or "natural" sciences (Burger, 1976: p. 68; cf. Weber, 1980: p. 9). He also regarded as Rickert an individual phenomenon as a unique combination of general causal laws. Therefore I can only conclude that Weber demanded nomological knowledge as a prerequisite for the description of singular historical phenomena. And the fact that neither sociology nor economics were able to provide such general laws and concepts in Weber's time forced him to develop these general concepts by himself. This is the reason for his later change of interest from historical economics to theoretical sociology. However, the point is that Weber was interested in historical as well as nomological knowledge, and this leaded him to the problem of the truth of general statements, because descriptions of historical events must be wrong, if the elements - the general causal laws - in the construction of the individual type are wrong. This conclusion contradicts Burger's hypothesis $\mathrm{B}_{2}$ that Weber demanded as only scientific procedure the selection of relevant elements out of the infinite reality, because in my interpretation the validity of the individualizing method forced him to deal also with the validity of the generalizing method. Regarding the generalizing sciences Weber re- 
jected under the influence of Hume and Kant both methods of inductive verification and intuition. He called as a consequence the general concepts "ideal types", because the truth of these general concepts cannot be guaranteed. Regarding the individualizing sciences Weber rejected Rickert's solution of objective concepts based on an ultimate cultural value, because Weber did not believed in the existence of such an objective value. As a result he called also the individual concepts "ideal types", because an arbitrary selection of the infinite elements cannot be avoided (cf. Weber, 1985: pp. 4, 14, 75 n. 2, 92 n. 1, 171, 177, 237; Burger, 1976: p. 65). Weber's “ideal types" are in this sense a solution to the problem of truth of scientific statements. His solution is a radical break with a several thousand-year-old philosophical tradition (Voegelin, 1952: p. 20) and it is a consequent application of the critical results of Hume and Kant (cf. Turner \& Factor, 1984: p. 38). If we cannot assure the truth of our scientific statements, then we must stop to claim their objectivity (cf. Turner \& Factor, 1984: pp. 34, 36-37). Therefore Weber regarded "ideal types" as a priori chosen but not a priori true. This is a clear distinction to Menger's methodological essentialism. They are based on subjective values and interests of the researcher. They are intersubjective understandable but not necessary accepted by all researchers. For example, a sociologist of the Critical Theory can understand Weber's ideal types, but he will probably reject them inclusive Weber's approach, because for him Weber's values lacked a "critical" attitude. This is obviously a distinction to Rickert's methodology based on objective values.

But Weber also declared that an objective historical science is possible, although every history is written from a specific viewpoint determined by the subjective values of the researcher. Weber's solution demands of every researcher clear definitions of the a priori and arbitrary chosen general concepts. The clear definitions are necessary for other researchers to understand the taken perspective. And the objectivity is guaranteed by the logical consistent application of this viewpoint, because every researcher who applies this understandable perspective will see the described phenomenon in the same way. Therefore can the results of the historical sciences be objective, although they necessary depend on subjective values and viewpoints. I will call this solution of logical deductions out of subjectively chosen perspectives the postulate of internal consistency. Once the subjective viewpoint is taken the scientific procedure has to be applied objectively and this means logically consistent. This is what Weber had in mind, when he demanded the absence of value judgements in the application of general concepts, although obviously every research approach is based on them.

My interpretation of Weber's methodology contradicts now Burger's interpretation in several points. First of all, I agree with Burger that Weber accepted the Neo-Kantian distinction of generalizing and individualizing sciences and general laws are used to describe individual historical phenomena. However, I disagree with Burger that Weber regarded "ideal types" as objective valid, research perspectives as determined by objective general cultural values, and the problem of the validity of nomological knowledge as unimportant. In my opinion Weber's position differed in the following points:

1) He rejected the idea that ideal types are objective true, because he saw no solution for the method of abstraction in the generalizing and individualizing sciences, which could guarantee the truth of general and individual concepts.

2) He therefore rejected every form of methodological essentialism.

3) Weber never accepted Rickert's objective values as foundation for his methodology.

4) Weber defined two concepts of causality: on the one hand causality as causal regularities in the sense of general laws and on the other hand causality as the causation of a phenomenon by subjective motives of human actors. And both concepts were equivalent important for him.

5) Therefore was sociology for Weber not just a complementary science for history, but the necessary foundation of an objective historical science.

6) And finally the objectivity of the historical sciences is for Weber guaranteed by the postulate of internal consistency and not by the construction of objective ideal types based on categories. Weber's unique solution for the methodological problems depends on the logical deductive application of general concepts and not in their inductive construction.

\section{The Method of Deductive Falsification for Text Interpretations}

Despite the differences of Thomas Burger's and my interpretation, I think that Burger (1976: p. 58) is offering a sufficient solution to the problem of truth in the individualizing sciences: not only the internal consistency of the deductions out of the chosen perspective but also the external consistency between the interpretation and the facts (the whole text or work) is important. 
What Burger calls here internal consistency is what I defined as the concept of external consistency. The internal consistency refers to the function of a theory as a heuristic tool. It is not the aim to test or confirm a theory but to apply it as a guide for an interpretation. And an interpretation is internally consistent, if all conclusions out of the premises are logically and therefore objectively understandable. An interpretation is on the other hand externally consistent, if the conclusions do not contradict with the facts. The aim is here to test the interpretation against the sentences in the text, and if contradictions occur, then the interpretation and the founding premises can be rejected. Burger's proposal is therefore nothing else than Karl Popper's method of deductive falsification. And I agree with Burger that this solution is better than Weber's postulate of internal consistency, because also wrong perspectives can be falsified in this approach. However, it is important to realize that although this solution is Popper's method of deductive falsification, it is not Popper's methodology, because Popper regarded the problem of truth in the individualizing sciences as unsolvable. History was just a collection of stories and therefore no science at all. He furthermore never considered the application of method of deductive falsification in text interpretations, because for him the meaning problem—as it was described in the Logical Positivism—was only an illusionary problem (Popper, 1989: p. 253).

Karl Raimund Popper's solution to the problem of truth in the natural sciences is the "testability" or "falsifiability" criterion. Popper's methodology starts with Hume's and Kant's insight that an inductive strategy —a strategy to induce out of subjective experiences more and more abstract theories—can never prove the truth of a theory (Popper, 1989: p. 3). But Popper realized that theories can still be proven to be wrong by the method of deductive falsification, although the verification approach is not logically justified. A theory is falsified if a prognosis deduced out of the theory does not stand the test against reality (Popper, 1987: p. 104). But if a theory survives the test, any conclusion about the truth of this theory is not allowed, because it still could fail in the future (Popper, 1989: p. 15). An objective causal explanation consists of two types of sentences: general sentences -hypothetical laws_-and specific sentences—initial conditions—which are only given in a concrete situation (Popper, 1989: pp. 31-32). Out of a combination of general and specific sentences a prognosis can be derived, which can be tested against the basic sentences-statements about singular facts. If contradictions occur between the projected results and the basic sentences, then a general statement must be wrong. In other words, Popper's solution is an extended version of Weber's: Popper demanded not only the internal consistency of theoretical systems but also their external consistency. More generally formulated, Popper said that contradictions are a bad sign in every case, because they indicate that something is wrong. I guess that most scientists can accept this sentence and I have no doubt that this insight can be applied also to the individualizing sciences and to text interpretations. In relation to text interpretations the method of deductive falsification means therefore that a hypothetical scheme of interpretation is falsified, if it leads to conclusions (the prognosis in the empirical sciences), which contradict some (basic) statements of the interpreted text.

However, the application of the method of deductive falsifications to text interpretations leads to some problems. First of all, we can only apply this method, if we assume that the interpreted text is logical consistent. This assumption implies that contradictions are the result of a wrong scheme of interpretation and not of the illogical thoughts of the author or of his insufficient ambiguous writing style. Obviously this is a very strong assumption, which I am not willing to make in every case. Therefore, this approach is restricted to specific logical scientific texts. However, I do not think that this point renders the method of deductive falsification for text interpretations irrelevant, because I see no reason to study a scientific text, which is illogical nonsense or just tautological. From such a text we could learn nothing about reality (the reality is in this case the author's ideas ${ }^{5}$ ).

The second problematic point is related to Popper's demand of repeatable falsifications. Contradictions alone are for Popper a necessary but not a sufficient criterion. Accepted basic sentences falsify a theory only if the singular facts stated in the basic sentences can be repeated and can be causally explained by an alternative hypothesis (Popper, 1989: pp. 54-55). This is a problem for text interpretations, because texts are singular phenomena with a finite number of sentences and therefore not repeatable ${ }^{6}$. This means that falsifications of text in-

\footnotetext{
${ }^{5}$ Alfred Schutz's distinction of first order and second order constructs is here important. In the natural sciences the researcher constructs first order models of the reality (the causal regularities in the nature). But in the social sciences two types of realities coexist. Some social scientists (like Marx and Parsons) construct first order models of the social reality (the causal regularities in the society or the regularities of the social system). Others (like Weber and Schutz) also modulate second order constructions of the actor's constructions of the social reality (the actor's knowledge, ideas, and beliefs about the social and natural reality). In the case of text interpretations only the second order constructs are important. The aim is to find out what the author wanted to say and how he saw the reality and not if his beliefs or ideas about reality were correct.

${ }^{6}$ Texts are not repeatable but they are expandable. The author can add other texts to clarify or to change his position.
} 
terpretations will be based on much less evidence than falsifications of general statements in the natural sciences, there in ambiguous cases a series of empirical tests can help to clarify the evidence. This leads to the problem that in some cases it will be impossible to decide which scheme of interpretation produces fewer contradictions. A point can be reached there a further development of an interpretation cannot be accomplished.

However, besides of these difficulties at least in one aspect the application of the method of deductive falsification in text interpretations has an advantage over the application in the empirical sciences. The facts stated in basic sentences are unquestionable given in the form of written sentences in the texts, there as basic sentences in the empirical sciences are only conjectures based on observations. These conjectures are accepted, if the researchers can reach a consensus (Popper, 1989: p. 73). It is obviously that this gives the falsification approach in the empirical sciences a weak basis.

My conclusion is that although the application of the method of deductive falsification to text interpretations is not unproblematic, it is necessary in accordance with Burger that schemes of interpretations that produce contradictions are avoided. And this task is most effectively accomplished with the method of deductive falsification.

\section{The Method of Falsification Applied to the Interpretation of Weber's Methodology}

I will follow now Burger's suggestion of "testing" his and mine interpretation of Max Weber's methodology. I will regard the scheme of interpretation that leads to more contradictions as falsified. And the surviving hypothetical scheme as corroborated as long as no other evidence is shown.

My hypothesis is that Max Weber was facing the problem of the objectivity of the historical sciences as defined by Burger. But the point that Weber constructed individual concepts out of a unique constellation of general concepts forced him to deal with the problem of truth in the individualizing as well as the generalizing sciences. Weber's problem can therefore be formulated as an extended version of Kant's problem:

$\mathrm{E}_{1}$ How are "natural" (generalizing) and "historical" (individualizing) sciences possible?

And Weber solved this problem in a unique way, by accepting the subjectivity and arbitrariness of the general and individual concepts and by demanding the internal logical consistency of the derivations out of these a priori given concepts.

I will propose a list of basic sentences to evaluate the potential of the two given schemes of interpretation.

$e_{1}$ The concepts and "laws" of pure economic theory are examples of this kind of ideal type. (Weber, 1968: p. 9; [1980: p. 4])

$\mathrm{e}_{2}$ Developmental sequences too can be constructed into ideal types [․․ (Weber, 1949: p. 101; cf. p. 103 [1985: p. 203; cf. p. 205])

The first two statements $\mathrm{e}_{1}$ and $\mathrm{e}_{2}$ of Weber indicate that for him micro- and macro-regularities or causal laws are ideal types.

$b_{1}$ The ideal-typical concept will help to develop our skill in imputation in research: it is no "hypothesis" but it offers guidance to the construction of hypotheses. It is not a description of reality but it aims to give unambiguous means of expression to such a description. (Weber, 1985: p. 190; proposed and translated by Burger, 1976: p. 121)

$\mathrm{b}_{2}$ Those interpretative schemas [TB: ideal types] $\cdots$ are not only "hypotheses" in analogy to the hypothetical "laws" of natural science. When concrete processes are heuristically interpreted, they can function as hypotheses. But in contrast to the hypotheses of the natural sciences the insight that in a concrete instance they do not contain a valid interpretation does not affect their usefulness for the establishment of knowledge $[\cdots]$. (Weber, 1985: p. 131; proposed and translated by Burger, 1976: p. 204 n. 31)

$\mathrm{e}_{3}$ In order to penetrate to the real causal interrelationships, we construct unreal ones. (Weber, 1949, pp. 185186 [1985: p. 287])

Combined with the statements $\mathrm{b}_{1}, \mathrm{~b}_{2}$, and $\mathrm{e}_{3}$ this means that for Weber general causal laws as well as individual historical concepts are not real—not even hypothetical—and it makes any sense to falsify them. Ideal types are nothing more than a heuristic tool. I can only conclude out of these statements that ideal types are not objective true. This supports my interpretation, that Weber regarded any solution for the method of abstraction in the generalizing and individualizing sciences as logically valid and that therefore the truth of general and individual concepts cannot be justified. Burger has severe problems to make sense out of these statements in his in- 
terpretation. He solves the problem—without giving reference to Weber-by stating that ideal types are objective true, but they would be only causal laws, if the reality is as we imagined it (Burger, 1976: p. 133). Obviously, Burger's and my definition of "objective" seems to be a little bit different. I am only willing to call something "objective", if it corresponds to reality. On the other hand I am not certain how Burger defines "objectivity", but I guess that he had probably something like "intersubjectivity" in the sense of shared beliefs about the reality in mind. However, I cannot see how this should support Burger's interpretation that for Weber ideal types are objective as the result of the application of an inductive procedure.

On the other hand Burger proposed another statement $b_{3}$ which clearly supports his interpretation and which produces problems in my interpretation.

$\mathrm{b}_{3}$ The objective validity of all empirical knowledge rests exclusively upon the ordering of the given reality according to categories which are subjective in a specific sense, namely in that they present the presuppositions of our knowledge and are based on the presupposition of the value of those truths which empirical knowledge alone is able to give us. (Weber, 1985: pp. 212-213; proposed and translated by Burger, 1976: p. 70)

The first part of this statement is Kant's solution to the question how science or more concrete how Newton's theory is possible. He avoided the invalid methods of inductive verification and intuition by claiming that our mind is forcing order on the chaotic reality ${ }^{7}$. And the pre-empirical categories—as for example the category of causality —are producing this order. The second part is Rickert's extension of Kant's solution: not only are the biological given categories but also the cultural values pre-empirical. I can only assume that Weber adopted here the language of Rickert, although he was well aware that "objective" in this sentence does not mean that the application of categories and values produces true knowledge. Marianne Weber reports Weber scepticism against Rickert's terminology in statement $\mathrm{e}_{4}$.

$\mathrm{e}_{4}$ I have finished Rickert. He is very good; in large part I find in him the thoughts that I have had myself, though not in logically finished form. I have reservations about his terminology. (Weber, 1975: p. 260 [1984: p. 273])

I think that Weber refers in this comment to Rickert's usage of the word "objectivity". In this sense he would not have a problem with Rickert's methodology as long as he does not claim that his method of defining concepts can guarantee the truth of general or individual statements. Therefore Weber uses consequent the term "ideal type" instant of the terms "concept" or "law". However, I need an auxiliary assumption, which I cannot support further with Weber's statement, to avoid a contradiction with my interpretation. As a result the previous statements support neither Burger's nor my interpretation.

But regarding the next point, all statements $\mathrm{b}_{1}, \mathrm{~b}_{2}, \mathrm{e}_{1}-\mathrm{e}_{4}$ corroborate my interpretation that Weber rejected every form of methodological essentialism, because the basic idea of the methodological essentialism is that essences are true. The first statements clearly contradict this idea. And even the statement $\mathrm{e}_{4}$ does not support this view, because Kant's categories are applied to the observable reality (physics) and not to the essences in the background (metaphysics). This point confirms my interpretation and contradicts the impression about Weber given by Burger.

The following statements refer to the main question, if Weber did or did not accepted Rickert's objective values as foundation for his methodology.

$\mathrm{b}_{4}$ The historian is "free" as far as the choice of the guiding values is concerned which in turn determine the selection and formation of the "historical individual" $[\cdots]$ which is to be explained. From here on, however, he is absolutely bound to the principles governing the establishment of causal interdependences. He is "free" in a certain sense only as far as the inclusion of logically "accidental" elements is concerned. (Weber, 1985: p. 124 n. 1; proposed and translated by Burger, 1976: p. 81)

$b_{5}$ There is no absolutely "objective" scientific analysis of culture—or put perhaps more narrowly but certainly not essentially differently for our purposes_of "social phenomena" independent of special and "one-sided" viewpoints according to which — expressly or tacitly, consciously or unconsciously - they are selected, analyzed and organized for expository purposes. (Weber, 1985: p. 170; proposed and translated by Burger, 1976: p. 88)

$\mathrm{b}_{6}$ Now, without any question are all those value-ideas "subjective”. (Weber, 1985: p. 183; proposed and translated by Burger, 1976: p. 87)

The basic sentences $b_{4}-b_{6}$ support only the common interpretation that Weber did not accepted Rickert's ob-

${ }^{7}$ In contrast to Kant's solution, there the perceived reality is determined by the mind, is in the inductive method the reality determining the images in the mind completely (verification) or partially (intuition). 
jective values. Values are chosen freely, they are one-sided and subjective. Nothing indicates Burger's main assumption that Weber was using Rickert's methodology without any critical distance. However, Burger tries to corroborate his interpretation with the following statement $b_{7}$ there Weber mentioned "universal cultural values". $b_{7}$ When we require from the historian and the social research worker as an elementary presupposition that he distinguish the important from the unimportant and that he should have the necessary "point of view" for this distinction, we merely mean that he must understand how to relate the events of reality-consciously or unconsciously - to universal "cultural values" and then to select those relationships which are significant for us. (Weber, 1985: p. 181; proposed and translated by Burger, 1976: p. 82)

But is this really Weber's standpoint? It follows directly the passage $e_{5}$ there he criticizes researchers who believe in the objective determination of a correct perspective. And he finally stated in the basic sentence $b_{8}$ that it is a personal matter of which perspective is chosen.

$e_{5}$ If the notion that those standpoints can be derived from the "facts themselves" continually recurs, it is due to the naïve self-deception of the specialist who is unaware that it is due to the evaluative ideas with which he unconsciously approaches his subject matter, that he has selected from an absolute infinity a tiny portion with the study of which he concerns himself. (Weber, 1949: p. 82 [1985: p. 181])

$\mathrm{b}_{8}[\cdots]$ the investigator's \{personal\} belief $[\cdots]$, the refraction of values in the prism of his mind gives direction to his work. (Weber, 1985: p. 182; proposed and translated by Burger, 1976: p. 85; in braces is the translation by Shils and Finch [Weber, 1949: p. 82])

Burger can only avoid a contradiction by formulating the auxiliary assumption that an objective history is possible, if a complete history is written from all cultural viewpoints, although different cultural values exist and the researchers are free to choose between them. But Burger has to admit that Weber never said so. As a result, it is much easier to interpret the statements $b_{4}-b_{8}$ and $e_{5}$ in my scheme than in Burger's. Therefore my interpretation that Weber rejected objective values is supported.

The next point concerns the question what Weber understood under the term "causality". Statement $\mathrm{e}_{6}$ shows that Weber made a distinction between two concepts of "causality": the first concept is based on the idea of a temporal connection between two individual phenomena (something unique is "caused" by something previously unique) and the second concept derives from the idea of a regular connection between two phenomena (cause and effect as a law). The first concept as a temporal connection between individual phenomena can be thought as a macro-connection between historical situations (e.g. the treatise of Versailles was leading to Hitler's rise) or as a micro-connection between the actor's motives and the result of their actions. Statement $e_{7}$ indicates that Weber regarded the micro-connection as the relevant temporal cause for individual phenomena.

$\mathrm{e}_{6}$ In its full-one might say: its "original”- sense, [the category of causality] has two components: on the one hand, the idea of "having an effect", as a (so to speak) dynamic link between phenomena that are qualitatively different from one another; on the other, the idea of being bound by "rules". (Weber, 2012: pp. 86-87 [1985: pp. 134-135])

$\mathrm{e}_{7}$ A causal approach will also embrace the "internal" aspect of the process, as well as the idea that an act "has to be brought about", the balancing of the "means" and, finally, the consideration of the "purpose" [of the action]: in a causal investigation, all these phenomena, and not just the "external" ones, will be treated as being strictly determined. (Weber, 2012: p. 227 [1985: p. 361]; emphasis added)

The question is now, if Weber demanded an analysis of the actors' motives or the forces of objective situation as important for the social sciences. Burger suggests that Weber's method of Verstehen only refers to the motives of the actor's and not to the objective situation in the sense of sociological or economic laws (e.g. the law of the decreasing marginal utility ${ }^{8}$ ). However, the statements $\mathrm{e}_{8}$ and $\mathrm{e}_{9}$ support my interpretation that both aspects are relevant for Weber, and that his approach is identical with the basic idea of Menger's marginal utility theory without the rationality assumption.

$\mathrm{e}_{8}$ "Meaning" may be of two kinds. The term may refer first to the actual existing meaning in the given concrete case of a particular actor, or to the average or approximate meaning attributable to a given plurality of actors; or secondly to the theoretically conceived pure type of subjective meaning attributed to the hypothetical actor or actors in a given type of action. In no case does it refer to an objectively "correct" meaning or one, which is “true” in some metaphysical sense. (Weber, 1968: p. 4 [1980: p. 1])

\footnotetext{
${ }^{8}$ The law of the decreasing marginal utility can for example explain why caviar is cheap in Russia but expensive in America without referring to the tastes of Russians and Americans. If Russians consume more caviar than Americans, then they will value caviar less because it will be nothing special anymore.
} 
$\mathrm{e}_{9}$ In all these cases understanding involves the interpretative grasp of the meaning present in one of the following contexts: 1 ) as in the historical approach, the actually intended meaning for concrete individual action; or 2) as in cases of sociological mass phenomena, the average of, or an approximation to, the actually intended meaning; or 3 ) the meaning appropriate to a scientifically formulated pure type (an ideal type) of a common phenomenon. (Weber, 1968: p. 9 [1980: p. 4])

Both statements are formulated analogous consisting of three parts. Basic sentence $\mathrm{e}_{8}$ refers to the "sense connections" of the actor. The first part describes the subjective (and individual) motive of the actor, the second part concerns the objective regularities of the situation, and the third part refers to the meanings of the ideal types $^{9}$. Basic sentence $e_{9}$ concerns the understandable "sense attribution" of the scientist through constructions of general types (the third part) and their applications to individual (the first part) and regular or general phenomena (the second part). The method of Verstehen therefore clearly includes the explanation of causal regularities and does not only deal with the subjective motives of the actors. The same attitude is stated in the basic sentences $\mathrm{e}_{10}$ and $\mathrm{e}_{11}$ there the method of Verstehen includes causal explanations.

$\mathrm{e}_{10}$ Thus causal explanation depends on being able to determine that there is a probability, which in the rare ideal case can be numerically stated, but is always in some sense calculable, that a given observable event (overt or subjective) will be followed or accompanied by another event. A correct causal interpretation of a concrete course of action is arrived at when the overt action and the motives have both been correctly apprehendedand at the same time their relation has become meaningfully comprehensible. A correct causal interpretation of typical action means that the process that is claimed to be typical is shown to be both adequately grasped on the level of meaning and at the same time the interpretation is to some degree causally adequate. (Weber, 1968: pp. 11-12 [1980: p. 5]; emphases added)

$\mathrm{e}_{11}$ However, sociology would protest against the assumption that [interpretative] "understanding" and causal "explanation" have no relationship with another. It is true that they begin their work at opposite poles of what happens. $[\cdots]$ But nevertheless, mental interrelations that can be understood in terms of their meaning, and in particular motivational sequences oriented according to purposive rationality, can certainly qualify as links in a chain of causation that, for instance, begins with "external" circumstances and at the end again leads to "external” behaviour. (Weber, 2012: p. 279 [1985: pp. 436-437]; emphasis added)

And the following statements $\mathrm{e}_{12}$ and $\mathrm{e}_{13}$ show that for Weber neither regularity nor understandable motives alone are enough for sociological rules. Only in their combination can knowledge in the social sciences produced.

$\mathrm{e}_{12}$ Statistical uniformities constitute understandable types of action, and thus constitute sociological generalizations, only when they can be regarded as manifestations of the understandable subjective meaning of a course of social action. Conversely, formulations of a rational course of subjectively understandable action constitute sociological types of empirical process only when they can be empirically observed with a significant degree of approximation. (Weber, 1968: p. 12 [1980: p. 6]; emphases added)

$\mathrm{e}_{13}$ It is customary to designate various sociological generalizations $[\cdots]$ as "laws". These are in fact typical probabilities confirmed by observation to the effect that under certain given conditions an expected course of social action will occur, which is understandable in terms of the typical motives and typical subjective intentions of the actors. (Weber, 1968: p. 18 [1980: p. 9]; emphases added)

The basic sentences $\mathrm{e}_{6}-\mathrm{e}_{13}$ corroborate my interpretation and they contradict Burger's. For Weber objective causal regularities and the subjective motives of the actors as the causes of actions are equivalent relevant for the analysis of historical phenomena. And if causal regularities are important for the historical sciences, then it is obvious that a specialized science has to provide such causal laws. And it is rather unimportant if for Weber sociology was a complementary science for the historical science or the necessary foundation of an objective historical science. It is unquestionable that Weber developed a great interest in a generalizing sociology.

The last point of discussion is the question what guaranteed for Weber the objectivity of the historical science: the logical consistent deductive application of general concepts as in my interpretation or their inductive construction based on categories as in Burger's interpretation.

$\mathrm{b}_{9}$ Undoubtedly, the value ideas are "subjective”. [] But obviously, it does not follow from this that research in the cultural sciences can only have results that are "subjective" in the sense of being valid for one person but not for another. Rather, what varies is the degree to which such results interest one person but not another.

\footnotetext{
${ }^{9}$ I translate Sinn as "sense” and not as "meaning”, because only the third part of the definition is dealing with the meaning of concepts.
} 
In other words: what becomes the object of investigation $[\cdots]$ that is determined by the value ideas that govern the scholar and are dominant in his age. As far as the method of investigation is concerned-how it proceeds-the guiding "point of view" [ $\cdots]$ \{determines the formation of the conceptual tools employed by the scholar; but, in applying these tools, \} he is obviously, here as everywhere else, bound to the norms governing our thought [‥]. (Weber, 2012: p. 121 [1985: pp. 183-184]; proposed by Burger, 1976: p. 89; the part in braces was missing in Burger's translation; emphases added by CE)

Statement $b_{9}$ indicates that the construction depends on the values, but since they are subjective and arbitrarily chosen, they cannot guarantee the objectivity of the historical sciences. But the application of the ideal types can justify an objective historical science, if it follows the "norms of our thinking". And "norms" cannot refer in this sentence to an "intersubjectively accepted standard of selection" (Burger, 1976: p. 89), because the selection of relevant aspects is a problem of the inductive construction of ideal types and not a problem of the application. Therefore, I conclude that "norms of our thinking" are the rules of logic (Turner \& Factor, 1984: p. 34), which again supports my interpretation that Weber's solution to truth problem in the generalizing and individualizing sciences is the postulate of internal consistency and that every research is based on an arbitrary subjective point of view.

Which hypothesis fits therefore better to the basic sentences proposed here? It is my interpretation, although also my interpretation cannot avoid contradictions completely. As a result Burger's hypothesis $\mathrm{B}_{1}$ and $\mathrm{B}_{2}$ as well as his interpretation that Weber only used Rickert's methodology without any substantial development are falsified. However, this does not mean that my interpretation is true. It stays a conjecture, a hypothesis. Other researchers are invited to add other basic sentences and to test alternative hypotheses against mine. A guideline for new contributions can be formulated as follows:

1) Give a new perspective: formulate a new hypothesis about Weber's problem, which can guide the interpretation.

2) Add new basic sentences: extend the list of Weber's statements, but do not delete already given sentences.

3) Question already given basic sentences:

4) Weber never wrote this. Preference should be given to the last authorized edition by the author or, if it was published posthumous, then the first edition should be preferred. And the original language should be preferred over translations.

5) Weber wrote this, but in a specific context: e.g. if the author criticized somebody else.

I will regard my hypothesis and my interpretation as falsified, if another hypothesis (after adding new basic sentences) produces fewer contradictions in the interpretation. It seems to me that Burger was right to propose a method of deductive falsification for text interpretations. It is a good method to exclude wrong interpretations, although it does not guarantee the truth.

\section{References}

Antoni, C. (1959). From History to Sociology. Detroit, MI: Wayne State University Press.

Burger, T. (1976). Max Weber's Theory of Concept Formation. Durham: Duke University Press.

Fleischmann, E. (1964). De Weber à Nietzsche. Archives Européennes de Sociologie, 5, 190-238. http://dx.doi.org/10.1017/S0003975600001004

Freund, J. (1968). The Sociology of Max Weber. New York: Pantheon Books.

Hansen, R. (1968). Der Methodenstreit in den Sozialwissenschaften zwischen Gustav Schmoller und Karl Menger. In A. Diemer (Ed.), Beiträge zur Entwicklung der Wissenschaftstheorie im 19. Jahrhundert (pp. 137-173). Meisenheim: Hain.

Hayek, F. A. (1973). The Place of Menger's Grundsätze in the History of Economic Thought. In J. R. Hicks, \& W. Weber (Eds.), Carl Menger and the Austrian School of Economics (pp. 1-14). Oxford: Oxford University Press.

Hennis, W. (1994). Die volle Nüchternheit des Urteils. In G. Wagner, \& H. Zipprian (Eds.), Max Webers Wissenschaftslehre (pp. 105-145). Frankfurt: Suhrkamp.

Honigsheim, P. (1968). On Max Weber. New York: Free Press.

Hume, D. (1978). A Treatise of Human Nature. Oxford: Clarendon Press.

Menger, C. (1883). Untersuchungen über die Methode der Socialwissenschaften, und der Politischen Oekonomie insbesondere. Leipzig: Duncker \& Humblot.

Menger, C. (1985). Investigations into the Method of the Social Sciences with Special Reference to Economics. New York/ London: New York University Press. 
Popper, K. R. (1987). Das Elend des Historizismus (6th ed.). Tübingen: Mohr.

Popper. K. R. (1989). Logik der Forschung. Tübingen: Mohr.

Rickert, H. (1921a). Der Gegenstand der Erkenntnis (4th/5th ed.). Tübingen: Mohr.

Rickert, H. (1921b). Die Grenzen der naturwissenschaftlichen Begriffsbildung. Tübingen: Mohr.

Rickert, H. (1921c). Kulturwissenschaft und Naturwissenschaft (4th/5th ed.). Tübingen: Mohr.

Scaff, L. A. (1984). Weber before Weberian Sociology. British Journal of Sociology, 35, 190-215. http://dx.doi.org/10.2307/590232

Schluchter, W. (1989). Rationalism, Religion, and Domination: A Weberian Perspective. Berkeley/Los Angeles/Oxford: University of California Press.

Tenbruck, F. H. (1959). Die Genesis der Methodologie Max Webers. Kölner Zeitschrift für Soziologie und Sozialpsychologie, 11, 573-630.

Turner, S. P., \& Factor, R. A. (1984). Max Weber and the Dispute over Reason and Value. London: Routledge.

Voegelin, E. (1952). The New Science of Politics: An Introduction. Chicago, IL: University of Chicago Press.

von Schelting, A. (1934). Max Webers Wissenschaftslehre: Das logische Problem der historischen Kulturerkenntnis. Tübingen: Mohr.

Weber, M. (1975). Max Weber: A Biography. New York: John Wiley \& Sons.

Weber, M. (1984). Max Weber: Ein Lebensbild. Tübingen: Mohr.

Weber, M. (1949). Methodology of the Social Sciences. Glencoe: Free Press.

Weber, M. (1968). Economy and Society: An Outline of Interpretative Sociology (Vol. 1). New York: Bedminster Press.

Weber, M. (1980). Wirtschaft und Gesellschaft. Tübingen: Mohr.

Weber, M. (1985). Gesammelte Aufsätze zur Wissenschaftslehre. Tübingen: Mohr.

Weber, M. (2012). Collected Methodological Writings. London/New York: Routledge. 
Scientific Research Publishing (SCIRP) is one of the largest Open Access journal publishers. It is currently publishing more than 200 open access, online, peer-reviewed journals covering a wide range of academic disciplines. SCIRP serves the worldwide academic communities and contributes to the progress and application of science with its publication.

Other selected journals from SCIRP are listed as below. Submit your manuscript to us via either submit@scirp.org or Online Submission Portal.
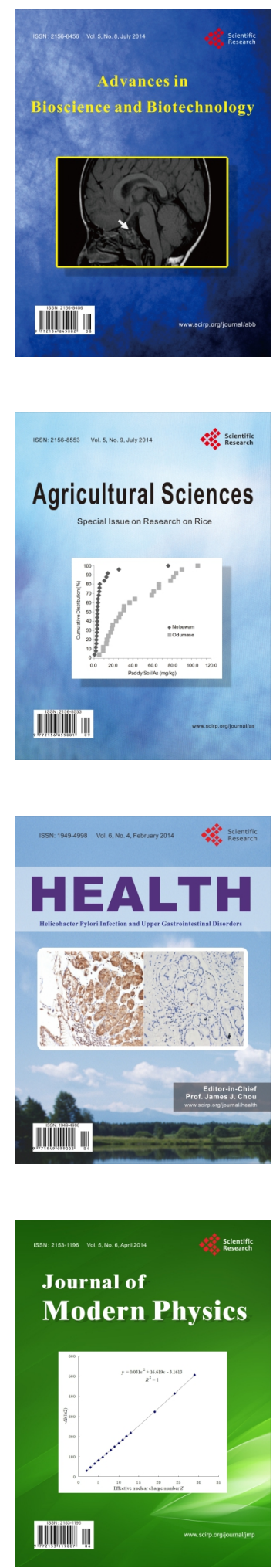
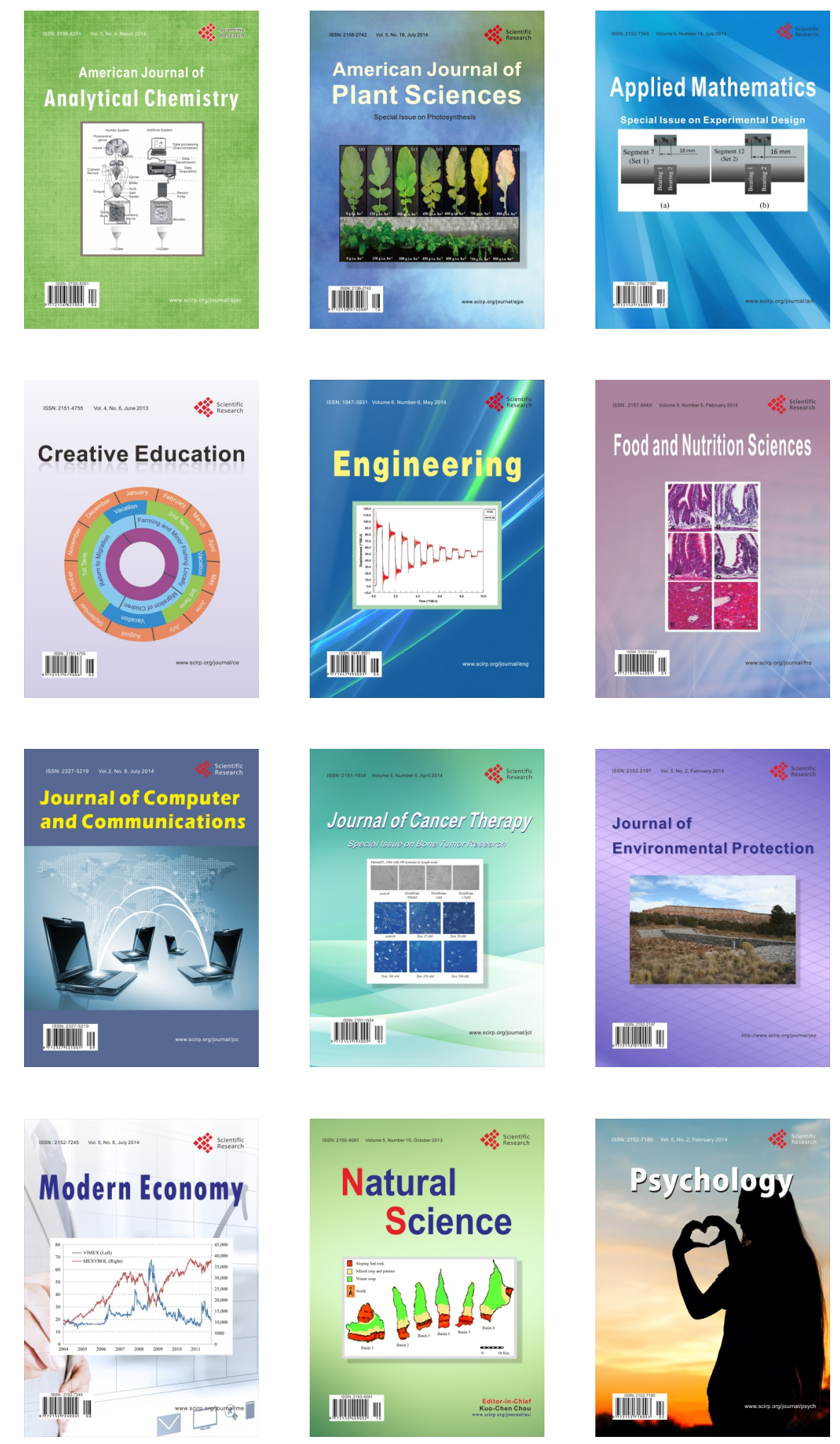